\title{
DEPOIS DO HOLOCAUSTO: EFEITOS COLATERAIS DO HOSPITAL COLÔNIA EM BARBACENA
}

\author{
AFTER THE HOLOCAUST: SIDE EFFECTS OF COLONY HOSPITAL IN BARBACENA \\ DESPUÉS DEL HOLOCAUSTO: LOS EFECTOS SECUNDARIOS DE LO HOSPITAL COLONIA EN \\ BARBACENA
}

\author{
Fuad Kyrillos Neto* \\ Christian Ingo Lenz Dunker**
}

\begin{abstract}
RESUMO
Este trabalho objetiva abordar os resquícios das práticas manicomiais executadas num grande hospital psiquiátrico e sua repetição nos serviços de saúde mental de Barbacena. Nessa instituição hospitalar, pessoas internadas involuntariamente, sem diagnóstico de doença mental foram violentadas e mortas com a conivência do Estado. Procedeu-se a um breve percurso histórico e crítico sobre a criação desse hospital e entrevistas com profissionais que nele trabalham e que participam da implantação das políticas públicas de atenção a saúde mental no município. A psicanálise será utilizada nesta investigação, como forma de abordar a violência política e social em seus efeitos traumáticos e continuados até a atualidade. O conceito de compulsão à repetição auxiliará na compreensão da manifestação de práticas e discursos ligados à cultura manicomial. Tais práticas se automatizam nesses profissionais que sofrem os efeitos das passagens inconscientes da história relegadas ao esquecimento por jogos de conveniência não explicitados.
\end{abstract}

Palavras-chave: Práticas manicomiais. Compulsão a repetição. Violência. História da psiquiatria mineira. Saúde mental.

\begin{abstract}
This research intends to address the remnants of insane asylum practices performed in a large psychiatric hospital and its repetition in the mental health services of Barbacena. In this hospital institution people were involuntarily admitted, without a diagnosis of mental illness, violated and murdered with the complicity of the state. Proceeded to a brief criticalhistorical analysis about it creation, interviews with professionals who work on it and, also, participate on the implementation of public policies on
\end{abstract}

\footnotetext{
Texto recebido em 11 de agosto de 2014 e aprovado para publicação em 14 de setembro de 2015.

* Doutor em Psicologia Social pela Pontifícia Universidade Católica de São Paulo (PUC/SP), integrante do Laboratório de Teoria Social, Filosofia e Psicanálise da Universidade de São Paulo (LATESFIP/USP). Docente do Departamento de Psicologia da Universidade Federal de São João del-Rei (UFSJ).E-mail: fuadneto@uol.com.br

** Psicanalista, professor livre-docente do Departamento de Psicologia Clínica do Instituto de Psicologia da Universidade de São Paulo (IPUSP). E-mail: chrisdunker@usp.br
} 
mental health care in the city. Psychoanalysis will be used on this research as a way to tackle the political and social violence in their traumatic effects that continues on these days. The concept of repetition compulsion will assist us in understanding the manifestation of practices and discourses related to asylum culture. Such practices are automated in those professionals who suffer the effects of unconscious passages of history, relegated to forgetfulness, by convenience games not specified.

Keywords: Mental hospital practices. Compulsion to repeate something. Violence. Minas Gerais psychiatry's development. Mental health.

\section{RESÚMEN}

Este trabajo tiene como objetivo hacer frente a los restos de las prácticas psiquiátricas realizadas en un gran hospital psiquiátrico y su repetición en los servicios de salud mental de Barbacena. En este hospital, las personas admitidas involuntariamente, sin un diagnóstico de enfermedad mental fueron violadas y asesinadas con la connivencia del Estado. Se ha producido un breve recorrido histórico y crítico en la creación de este hospital y entrevistas a profesionales que trabajan en ella y participar en la implementación de políticas públicas que aborden la salud mental en el municipio. El psicoanálisis se utilizará en esta investigación como una manera de hacer frente a la violencia política y social y sus efectos traumáticos continúa hasta hoy. El concepto de compulsión a la repetición ayudar en la comprensión de la manifestación de prácticas y discursos relacionados con la cultura de asilo. Tales prácticas si automatizan estos profesionales que sufren los efectos de los pasajes inconscientes de la historia relegados al olvido por los juegos de conveniencia no especificados.

Palabras-clave: Prácticas del asilo. Compulsión a la repetición. Violencia. Historia de la psiquiatría minería. Salud mental.

\section{INTRODUÇÃO}

D esde o início do século XX, a falta de critérios para internação e os maustratos com os internos eram corriqueiros no Hospital Colônia de Barbacena. O pensamento eugenista, difundido pela Liga Brasileira de Higiene Mental nos anos de 1920, ao adotar a ideia de prevenção eugênica, considerava todos aqueles portadores de transtornos psíquicos como degenerados (Costa, 2007). Tais ideias tiveram forte ressonância na psiquiatria mineira, contribuindo para a criação e expansão dos grandes hospícios mineiros (Magro, 1992).

Com o avanço do higienismo, a instituição psiquiátrica ganhou um lugar de destaque nos discursos médicos. Preocupando-se basicamente com o aspecto 
da formação moral dos indivíduos, o saber psiquiátrico voltou-se para uma perspectiva específica de higiene moral, complementando a tarefa estabelecida pela higiene pública. A psiquiatria se propôs a uma nova forma de higiene que deveria se passar no nível dos sentimentos e das paixóes. Desse ponto de vista, adquire relevância a noção de degeneração psíquica, que se caracteriza como uma perturbação neurológica, que produziria confusão nos sentimentos e pensamentos, tornando os indivíduos inaptos e nocivos à convivência social. Essa noção possibilita um notável avanço da estratégia médica. Nesse contexto, a psicanálise foi apropriada como saber normativo nas instituições psiquiátricas, conquistando um espaço valioso para seu desenvolvimento no país e contribuindo para a legitimação da adoção de práticas preventivas no tratamento dos doentes (Nunes, 1988).

Entre os precursores da psicanálise no Brasil, encontramos psiquiatras que trabalharam intensamente na construção dos grandes asilos brasileiros (Franco da Rocha, Juliano Moreira). No Rio de Janeiro, a ascensão de Juliano Moreira à direção do Hospital Pedro II foi saudada como um momento de modernização da psiquiatria brasileira (Russo, 2002). Em que pese sua filiação aos princípios da psiquiatria alemã, que denota o caráter sui generis da assimilação das ideias psicanalíticas no Brasil, nesse cenário a psicanálise apareceu como substrato ideológico no contexto de autonomização da psiquiatria brasileira.

Até meados da década de 1950, a psicanálise no Brasil conviveu com uma assimilação voltada para o controle e normalização da população, fruto de sua associação ao movimento higienista.

Porém, na presente discussão, nos interessa utilizar a psicanálise numa investigação que visa a abordar a violência política e social em seus efeitos traumáticos e continuados para uma cidade que abriga um enorme hospital psiquiátrico, no qual, durante décadas, pessoas foram internadas a força, sem diagnóstico de doença mental, e posteriormente foram torturadas, violentadas e mortas com a conivência do Estado.

Barbacena - que hoje conta com 128.572 habitantes - foi escolhida para abrigar o Hospital Colônia. (Barbacena, 2013). Esse foi o "premio de consolação" que a cidade recebeu por não ter sido eleita para ser a nova capital do Estado de Minas Gerais (Magro, 1992). A ideia de uma compensação pela perda da possibilidade de ser capital do Estado advém do fato de, naquele momento, o hospício ser considerado uma importante instituição pública e, nesse caso, a primeira do gênero em Minas Gerais, o que certamente atrairia recursos e investimentos para a cidade. 
Duarte (1996) relata que, por intermédio da lei n. 290, de 1900, o governo mineiro autorizou a compra da Companhia Sanatório Barbacena, localizada no Morro da Caveira de Cima, que fazia parte das terras de Joaquim Silvério dos Reis, o delator da causa da Inconfidência Mineira.

A autora afirma que nas escrituras, lavradas em cartório no dia 7 de novembro de 1894 e, igualmente, no ano de 1903, está registrada a configuração do imóvel e os nomes dos proprietários que formavam o Conselho da Companhia do Sanatório Barbacena. A localização do sanatório é no subúrbio da cidade de Barbacena, numa colina, com frente para a Estrada de Ferro Central do Brasil. A área do terreno é de oito alqueires, aproximadamente $40 \mathrm{mil} \mathrm{m}^{2}$, sendo $5 \mathrm{mil} \mathrm{m}$ formados por mata virgem, uma chácara com árvores frutíferas e uma pedreira. As melhorias do estabelecimento hospitalar constavam de dois chalés para os diretores, centros de oficinas, lavanderias, banheiros com duchas, o instituto de balneoterapia, alojamentos para doentes, refeitório e um salão de bilhar.

Em 1922 é anexada ao hospital uma colônia agrícola para assistência a alienados. Após inúmeras ampliações, construções e reformas, Toledo (2001), ex-diretor do Centro Hospitalar Psiquiátrico de Barbacena, nos lembra que o hospital conta "com uma estrutura comparável à de pequenas cidades do interior do Estado". Podemos aproximar essa afirmação ao que Dunker (2011a) designa como lógica do condomínio. Partindo da constatação de que pela lei brasileira um condomínio possui determinados poderes estabelecidos contra estranhos, o autor assevera que essa lógica tem por princípio excluir o que está fora dos seus muros. Portanto, a tensão entre a área demarcada que abriga o condomínio e seu exterior está suspensa, pois esse local é concebido e vivido como um falso universal.

Ao abrigar esse hospital, a cidade se colocaria no centro das atençôes da psiquiatria mineira. Barbacena tornou-se o ponto de referência no tratamento daqueles que eram diagnosticados como doentes mentais e passou a contar com a criação de uma rede de serviços composta por sanatórios particulares. $\mathrm{O}$ fato de a cidade ter se tornado referência da psiquiatria mineira pode ser explicado por ter ela acolhido a primeira instituição específica para doentes mentais no estado de Minas Gerais. Além disso, tal instituição estava em sintonia com o modelo psiquiátrico empregado em outros importantes hospitais do gênero no Brasil (Silva, 2008).

Assim como a cidade se contentou com o prêmio de consolação, parece-nos que a população se resignou com os efeitos desse prêmio no seu cotidiano. Nesse sentido, Silva (2008) nos apresenta um interessante depoimento publicado na revista da Associação Médica de Minas Gerais, sobre a assistência ao doente mental em Barbacena. 
É um espetáculo deveras deprimente, a que a população de Barbacena assiste constrangida, a passagem de doentes pelas ruas, malvestidos, estropiados e contrafeitos, como se fossem levas de gado tangido para o curral, em demanda do hospital, que dista uns dois ou três quilômetros da estação. Essa procissão macabra de espectros humanos desfila tristemente pela cidade procurando as ruas mais discretas para fugir à curiosidade popular. [...] isso se passa em um país onde os governantes e poderosos se resfolegam em cadillacs de luxo! (Alvim, apud Silva, 2008, p. 13).

Trabalharemos com fontes primárias obtidas nas visitas ao Museu da Loucura de Barbacena, documentos da Secretaria de Saúde e Assistência do Estado de Minas Gerais, reportagens publicadas na impressa local e regional, legislações referentes à assistência psiquiátrica produzida no Estado de Minas Gerais, livros que abordam a história da psiquiatria em Minas Gerais (Magro, 1992; Moretzsohn, 1989; Silva, 2008) e entrevistas com profissionais que trabalham no Centro Hospitalar e Psiquiátrico de Barbacena (antigo Hospital Colônia de Barbacena). A escolha dos entrevistados deveu-se a sua participação efetiva tanto no cotidiano do funcionamento da instituição hospitalar quanto na implantação das políticas públicas de atenção à saúde mental no município, que resultaram na instalação do Centro de Atenção Psicossocial do município de Barbacena, bem como na rede de apoio à saúde mental (Residências terapêuticas, Centro de Convivência).

No que tange à psiquiatria, não encontramos registros de uma participação efetiva desse profissional na implantação da reforma psiquiátrica no município. Lembramos que os hospitais psiquiátricos privados da cidade são dirigidos por psiquiatras. Sobre esse aspecto, o documento do Fórum Mineiro de Saúde Mental, intitulado Saúde Mental em Barbacena: graves retrocessos, nos fornece algumas indicações de tal afastamento. Esse documento, datado de 2002, sugere que o desmonte da equipe do CAPS municipal atende a interesses dos hospitais psiquiátricos privados. $\mathrm{Na}$ mesma época, novembro de 2002, uma matéria publicada no Jornal de Sábado, aponta que o CAPS municipal enfrenta "uma série crise política que pode até levar a entidade a ser descredenciada pelo Ministério da Saúde se não cumprir com as metas estabelecidas". Segundo a reportagem, a crise política começou com a demissão da gerente do CAPS e de mais oito funcionários pelo gestor da entidade, profissional da psiquiatria. Os funcionários do CAPS afirmam que a saída dos profissionais enfraqueceu ainda mais os objetivos iniciais da forma de tratamento mental da entidade. ("Crise política”..., 2002).

$\mathrm{Na}$ análise do material consultado, recorremos à teoria da psicanálise sobre trauma e recordação. Para Freud $(1914 / 1996)^{1}$ a verdade histórica de uma lembrança reside na recordação dos processos psíquicos e não somente em uma

1 A primeira data indica o ano de publicação original da obra e a segunda data inidca a edição consultada pelo autor, que só será pontuada na primeira citação da obra no texto. Nas posteriores será registrada apenas a data de publicação original. 
reprodução fiel da verdade dos fatos objetivos. O que se recorda são os eventos transformados e seu processamento psíquico. Esse autor considera um êxito do tratamento solucionar algo por intermédio de um trabalho de recordação, que o paciente queria remover pela ação. Por vezes isso não acontece. Frequentemente, aquilo que foi esquecido e recalcado, em vez de ser reproduzido como recordação, é repetido como ação. A compulsão à repetição substitui o impulso para recordar. É na transferência que se realiza esse processo, pois seu manejo possibilita o despertar das recordaçóes, que surgirão com a superação das resistências. Posteriormente, em Construçôes em análise, Freud (1937/1994) adotará maior cautela com relação ao despertar de recordaçôes. A despeito do desejo de obter um quadro confrável e completo dos anos esquecidos do paciente, em alguns casos será necessário contentar-se somente com as construções.

Com isso pretendemos nos servir da psicanálise num contexto diferente de seus primórdios na psiquiatria brasileira, que nos permita contestar as práticas psiquiátricas correntes no Hospital Colônia de Barbacena. Assim, mostraremos o efeito traumático da execução de tais práticas, acumulado na cultura, bem como seus efeitos na atualidade, por intermédio de uma mudança no sistema de exploração do paciente com vistas à manutenção da ordem psiquiátrica no Centro Hospitalar Psiquiátrico de Barbacena.

Essa forma de apropriação da psicanálise nos permite refletir acerca dos usos e aplicações dos discursos psi para a produção e reprodução das práticas sociais hegemônicas e a possibilidade do uso desses discursos para abertura de espaços de contestação de tais práticas.

Tais discursos, por intermédio da transformação histórica sofrida, silenciam algumas formas de sofrimento, nomeiam outras e atribuem valor moral ou indexadores de classe ou gênero para determinados sofrimentos. Essas considerações nos mostram a maciça presença da ideologia na definição de loucura.

\section{A CONSTRUÇÃO DO SISTEMA PSIQUIÁTRICO ASILAR EM BARBACENA: BREVE PERCURSO CRÍTICO-HISTÓRICO SOBRE A IMPLANTAÇÃO DA INDÚSTRIA DA LOUCURA}

Em agosto de 1900, foi sancionada a lei n. 290, que aborda a "creação da assistência de alienados" e a "instalação de hospícios". Em seu artigo terceiro, a lei especifica como devem ser as instalações do hospício: "No prédio que for destinado ao hospício haverá, além das accommodações precisas, um pavilhão para observação dos indivíduos suspeitos, um gabinete electro-therapico e officinas, quando necessárias e a juízo do governo" (Lei n. 290, 1900). 
A observação dos indivíduos suspeitos, presente nesse artigo, revela uma aproximação da loucura com a periculosidade e a consequente necessidade de controle.-

Nesse contexto, em fevereiro de 1903, o decreto n. 1.579 afirma: "fica creada, na cidade de Barbacena, a Assistência de Alienados, com uma colônia anexa que a completa, destinada a receber os habitantes do Estado que, por motivo de alienação mental, carecerem de tratamento" (Minas Gerais, 1903, apud Moretzsohn, 1989, p. 15). Mantém-se nesse decreto a obrigatoriedade do pavilhão de observação para indivíduos suspeitos de alienação.

Mas como controlar a loucura e a marginalidade que tanto preocupavam as elites? Nesse sentido o condomínio, na acepção proposta por Dunker (2009), como uma região isolada do resto, na qual se poderia conviver e partilhar o sentido de uma comunidade de destino, nos oferece algumas indicações. Cercado por muros o condomínio aponta que ali vigora um estado especial da lei. Os muros para não sair, progressivamente transformam-se em muros para não entrar. Esse cerco torna-se a tática hegemônica de controle. Firmino (1982) surpreende-se com a indiferença de setores da sociedade incomodados com suas reportagens sobre a vida dos pacientes intramuros, que sempre foi mantida como segredo. Como exemplo ele cita um editorial do jornal Cidade de Barbacena de abril de 1961 que afirma que:

[...] todas essas situações foram constatadas por uma equipe masculina de gente de imprensa, ávida por aproveitar a ocasião. E, por incrível que pareça, os repórteres devassam a intimidade do Departamento Feminino, onde há cerca de 3.000 dementes, portanto, 3.000 mulheres solteiras, casadas, viúvas e anciãs. Que dizer de tudo isso? (Jornal Cidade de Barbacena,1961 apud Firmino, 1982, p. 27)

A psicanálise nos ensina a desconfiar dessas iniciativas que se constituem como espaços de extraterritorialidade. Tais espaços levam a um sentimento de servidão que nos prende à repetição de uma rotina fantasmática. Tal rotina surge de forma descritiva nos inúmeros decretos e leis que tentam, sem êxito, regular a assistência aos internos da instituição.

Inferimos que nos decretos e leis posteriormente elencados a barbárie será reconhecida na figura dos indesejáveis, aqueles que contradizem a noção de que tudo está bem em nossa ordem social e precisam ser controlados, segregados e reeducados. O psiquiatra será aquele que, a partir do pressuposto de que as intenções objetivas e subjetivas são louváveis, aplicará as diretrizes contidas na legislação vigente de forma a obter a organização racional do espaço hospitalar. 
Em tais condições as ilusões ficam perigosamente próximas de sua realização efetiva. Nesse contexto, temos uma deposição da função de ideal, que é colocarse como negatividade futura, como da função de objeto, que é mostrar-se como ilusão de presença. A primeira possibilidade é designada por Dunker (2009) como utopia, enquanto a segunda é chamada por ele de atopia.

Quando a função reguladora de um ideal exercida pela utopia é substituída por um objeto encarnado, fica instituída a condição para o totalitarismo e a servidão voluntária. De fato, essa expectativa teórica se manifesta na rigidez assumida pelos decretos e leis que regulam a vida dos internos, conforme veremos a seguir.

Em 1920, em uma mensagem enviada ao Congresso Mineiro, o presidente do Estado de Minas Gerais, Arthur da Silva Bernardes, admitiu que as medidas tomadas até então não tinham resolvido satisfatoriamente o encargo moral e humanitário da assistência aos enfermos psiquiátricos. Uma das razões da reforma da assistência aos alienados, instituída em 1922, que anexou uma colônia agrícola à Assistência de Alienados de Barbacena e fundou, em Belo Horizonte, o Hospital Raul Soares, devia-se a falta de:

capacidade para o número crescente de loucos de todo o gênero, cuja guarda incumbe ao poder público, bastando assignalar que a Assistência está sempre repleta, com uma lotação muito superior à normal e que um sem-número de pedidos aguarda, constantemente, na Chefia de Polícia a ocorrência de vagas, enquanto os infelizes loucos povoam as cadeias ou vagam pelos povoados e estradas com risco próprio ou alheio (Bernardes, 1920 apud Moretzsohn, 1989, p. 27).

Essa mensagem de Arthur Bernardes faz menção à caótica situação da assistência aos pacientes psiquiátricos oferecida pelo hospício de Barbacena. Nesse documento encontramos ainda uma proposta de tratamento para os internos: "temos de adaptar e desenvolver a Colônia de Alienados por forma que o trabalho, clinicamente orientado como elemento de cura e não como factor econômico, complete o tratamento do médico da Assistência consoante o ensinamento de especialistas" (Bernardes, 1920 apud Moretzsohn, 1989, p. 27).

Em 1927, o presidente Antônio Carlos introduziu modificações na assistência psiquiátrica do Estado de Minas Gerais. Foi criado o hospital psiquiátrico de Oliveira e o Manicômio Judiciário de Barbacena. O hospital de Oliveira, fechado em 1976, transferiu trinta e três crianças para o Hospital Colônia de Barbacena, elas continuaram a viver em condições precárias. A lei n. 961, de setembro de 1927, subordina a Directoria de Saude Publica à Secretaria de Segurança e Assistencia Publica. Além dessa subordinação, o item 1 do artigo primeiro aponta que essa diretoria teria como serviço a "educação sanitaria da população", 
"o estudo de todas as questôes relativas á saude publica" e a "prophylaxia geral e especifica das doenças transmissiveis e de outras evitaveis". (Lei n. 961, 1927).

Naquele período, segundo consta na Instituto Raul Soares Primeira memória medico administrativa do serviço de assistencia a alienados, "o trabalho passou a ser de tal sorte, a terapêutica normal de seus habitantes, porque é a unica para a qual, quase em toda psychiatria, não há contraindicações”. (Rodrigues, 1930, p. 76).

Após frisar que o Instituto Raul Soares, em Belo Horizonte, se transformou "numa grande oficina", o então diretor, o psiquiatra Rodrigues (1930), autor dessa memória, que destaca a laborterapia na instituição, frisa que ela deveria ser acompanhada de um pecúlio para os pacientes:

[... ] dentro em um anno, abertas cadernetas de poupança na Caixa Economica, em beneficio daquelles que, capazes de uma pronunciada readaptação social, foram contemplados, após bons serviços, nas folhas de vencimentos do Instituto, ao passo que se iam verificando vagas para empregados (p. 76).

Essa medida adotada pelo Estado visava também à ressocialização de pacientes. Lembramos as assertivas de Dunker (2011b) acerca dos discursos psi para a produção e reprodução das práticas sociais hegemônicas. Temos, nesse momento, uma transformação histórica que atribui valor moral para o trabalho.

Porém, vemos que tal ideologia está relacionada a um trabalho que, pela descrição histórica, tinha motivação terapêutica, mas no cotidiano prestava-se a explorar a força de trabalho dos internos para a manutenção diária do hospício. Recentemente publicado, em que pese seu caráter jornalístico, o livro Holocausto brasileiro de Arbex (2013) retoma as discussões acerca desse episódio lembrandonos que registros da instituição do ano de 1916 apontam que quase metade da receita do hospício foi garantida com o trabalho dos pacientes e pela venda dos alimentos que eles plantavam. O faturamento era garantido ainda pelo uso da mão de obra dos internos no conserto de vias públicas, limpeza de pastos, preparação de doces e confecção de peças de roupas.

Os negócios com os internos não se restringiam à exploração da força de trabalho. Firmino (1982) aponta que o hospital foi o principal fornecedor de cadáveres para as faculdades de medicina. Em 1971, deputados mineiros denunciaram na Assembléia Legislativa o comércio de cadáveres entre o Hospital de Barbacena e as Faculdades de Medicina de todo o país. A única medida efetiva tomada foi o cancelamento dos convênios entre as faculdades e o hospital e a criação de um convênio no qual os cadáveres eram permutados por medicamentos, alimentos e roupas para os internos. 
No regulamento de 1927 é possível identificar a proposta de criação da Liga Mineira de Higiene Mental (LMHM). A questão da higiene mental foi debatida em Minas Gerais não apenas nos círculos psiquiátricos, mas o seu ideário foi divulgado em jornais e rádios. A questão da marginalidade, seja qual fosse, preocupava as elites, que buscavam de várias formas contê-la.

As ideias eugênicas alcançam proeminência nesse período no Brasil, sendo responsáveis por várias medidas de prevenção e higienização da sociedade. Em Minas Gerais, a aplicação da teoria eugenista, com seu patrulhamento moral, abriu caminho para a produção de cerca de milhares de mortes no Hospital Colônia de Barbacena. A administração municipal de Barbacena adotava medidas semelhantes: "A prefeitura de Barbacena, por exemplo, realiza verdadeiras "operaçôes de limpeza", ou melhor, de eugenização da cidade, para que possa livrar-se do epíteto de cidade dos doidos. E nesse arrastão, mendigos e vagabundos são levados para o hospital" (Moreira, 1983, p. 63).

Os "indesejáveis" deveriam ficar distantes do olhar da sociedade, cercados pelos muros de seu "condomínio". Tanto que um dos setores do hospital distava cerca de $6 \mathrm{~km}$ do centro da cidade, o que para os padróes da época era muito longe.

Podemos fazer uma aproximação dessa realidade com o que Foucault (1991) designa como a grande internação, que tem como elementos centrais o rompimento do diálogo com a loucura e sua exclusão da trama civilizatória. Tais elementos são fundadores do saber e do contexto terapêutico da psiquiatria. Nesse contexto, os "sujeitos fora da ordem" eram submetidos à internação como processo de exclusão em estabelecimentos que tinham funções tipicamente disciplinares e de manutenção da ordem social.

Em 1933, o interventor federal em Minas Gerais, Benedito Valladares Ribeiro, transformou a Inspetoria de Assistência Hospitalar em Diretoria de Assistência Hospitalar. A essa mudança de denominação seguiu-se o projeto apresentado pelo secretário de Educação e Saúde Pública, que criava um novo Regulamento de Assistência Hospitalar do Estado de Minas Gerais.

No projeto de reformulação apresentado ao presidente do Estado, notamos uma tendência de abrir espaço na política de saúde do Estado para as duas principais preocupações eugenistas, quais sejam: a melhoria na assistência e a preocupação com a prevenção.

Sobre a contínua crise que viviam os hospitais psiquiátricos públicos mineiros, a psiquiatria da época apresentava uma visão do problema com forte conotação religiosa, elencando entre suas causas a falta de amor ao próximo, ao lado de defeitos raciais e da imprevidência dos brasileiros. 
Em 1946, no governo do interventor João Beraldo, aconteceu a chamada reforma Alvino de Paula, que transformou a Directoria de Saude Publica em Departamento Estadual de Saude, desvinculado da Secretaria de Educação e Saude Publica e diretamente subordinado ao Chefe de Governo do Estado. Esse seria o cerne da futura Secretaria do Estado da Saúde.

Nesse ínterim, o chefe do Departamento de Assistência Neuro-Psiquiátrica do Estado de Minas Gerais, ex-diretor do Hospital Colônia de Barbacena, José Concesso Filho, em um documento datado de junho de 1959, sugere: "[ . . .] a transformação provisória dos pisos dos quartos de doentes indigentes desse hospital em um só leito, retirando a cama neles existentes de modo a comportar em cada um, oito a doze internos em vez de 3 ou 4 como se encontra atualmente" (Concesso, 1959)2.

No documento, o chefe do departamento aponta que essa solução há muitos anos vinha sendo adotada em Barbacena. A precariedade da situação do hospital de Barbacena foi utilizada como solução para o funcionamento limite de outra instituição psiquiátrica do Estado, o Instituto Raul Soares. Inferimos, por intermédio da análise dos documentos, que ressaltam a modernidade, a especialidade e o planejamento na nova reforma da saúde pública, que estávamos em um contexto histórico diferente do anterior. Porém, esse discurso da modernidade e do planejamento não deixa de revelar o paradoxo entre o discurso da Reforma Alvino de Paula e as precárias condiçôes de vida dos internos dos hospitais públicos mineiros.

Firmino (1982) lembra-nos que, após mais de meio século da fundação do hospital, a superlotação sempre foi constante. A substituição de camas por capim, chamado de leito-chão, durou até 1980, época do início das denúncias de maus-tratos e extermínio nos hospitais psiquiátricos brasileiros.

Destacamos que, durante o período da Ditadura Militar, os critérios médicos se tornaram menos importantes, conforme notamos em reportagem veiculada no jornal Tribuna de Minas "A instituição, transformada em um dos maiores hospícios do país, começou a inchar na década de 30, mas foi durante a ditadura militar que os conceitos médicos simplesmente desapareceram” (Arbex, 2011). Cumpre ressaltar que naquele período foi nomeado para ocupar o cargo de diretor administrativo do Hospital Colônia de Barbacena um coronel reformado do exército. Sua função era cuidar das compras e da infraestrutura oferecida aos pacientes, na ocasião em que Basaglia, visitando o hospital, fez as denúncias de maus-tratos e abandono dos pacientes. Lembramos que na obra que traz

2 Ofício n. 1.186 enviado por José Concesso Filho, chefe do departamento de assistência neuro-psiquiátrica da Secretaria de Saúde e Assistência do Estado de Minas Gerais, para Sílvio Cunha, diretor do instituto Raul Soares no dia 19 de junho de 1959. Acervo do Arquivo Histórico do Museu da Loucura em Barbacena, Minas Gerais. 
as conferências de Basaglia no Brasil, é relatado que a visita que fez ao Centro Hospitalar Psiquiátrico de Barbacena "teve sobre ele um impacto tão violento que o deixou profundamente deprimido" (Basaglia, 1979, p.136). Posteriormente, ao ser instigado a falar, fazendo uma alusão à era pré-pineliana, ele afirmou que "em algum lugar do mundo a história parou" (Basaglia, 1979, p.136).

Durante o período de vigência da ditadura militar, os tipos que mereceram "atenção política" do Estado, em condições sub-humanas semelhantes a era prépineliana, foram desafetos, homossexuais, militantes políticos, mães solteiras, alcoolistas, mendigos, pessoas sem documentos e todos os tipos de indesejados, inclusive, doentes mentais.

Este fato está em consonância com a assertiva de Dunker (2011a) que nos lembra que: "as modalidades de sofrimento tratáveis ou intratáveis, os tipos de mal-estar que merecem atenção política ou clínica, bem como as formas prevalentes ou divergentes de sintoma são um fenômeno há muito conhecido na história da medicina” (p. 45).

\section{A REDE DE SAÚDE MENTAL DE BARBACENA E SEUS “PINÉIS”}

Após uma década da implantação da lei federal n. 10.216, de 2001, que propõe um modelo de atenção à saúde mental aberto e de base comunitária, o Brasil experimentou uma redução nos leitos psiquiátricos de 50 mil para pouco mais de 30 mil leitos. Nesse período 45 hospitais psiquiátricos foram desativados, sendo que 200 continuam em funcionamento (Brasil, 2007).

Em contrapartida, foram instalados 1.620 Centros de Atenção Psicossocial (CAPS) até o ano de 2010 e 600 Serviços Residenciais Terapêuticos (SRT) em espaço urbano (Brasil, 2007). A portaria n. 106, de 2000, institui o Serviço Residencial Terapêutico como moradias assistidas, inseridas de preferência na comunidade, com objetivos de reinserção social, resgate da cidadania e autonomia dos moradores de longa data dos hospitais psiquiátricos, que não possuam suporte social e vínculos familiares, ou que, por outra razão, necessitem do serviço.

Conforme a Portaria 1.220 (2000), o SRT é um serviço com característica de moradia ou casa, visando à inserção social de seus moradores, sendo uma modalidade assistencial substitutiva da internação psiquiátrica prolongada. Nesse contexto, a pessoa que estava há longo tempo internada em hospitais psiquiátricos desfrutaria de alta hospitalar e da possibilidade de continuidade do cuidado no âmbito do SRT, que deveria estar integrado à rede articulada de serviços do SUS. 
$\mathrm{Na}$ década de 1980, após a imprensa veicular de forma maciça as precárias condições de vida dos internos no Hospital Colônia de Barbacena, foram tomadas medidas para a melhoria do serviço prestado naquela instituição. Tais medidas se basearam na estruturação do serviço pautada na adoção de critérios diagnósticos específicos e no encerramento de atividades supostamente terapêuticas, mas que no cotidiano institucional tinham finalidade punitiva.

No que tange à adoção de critérios diagnósticos, destacamos a proibição da transferência indiscriminada de pacientes do Instituto Raul Soares localizado em Belo Horizonte para o Hospital Colônia. Até aquele momento a prática dos médicos era encaminhar para Barbacena os casos não estabilizados em dez dias. $\mathrm{O}$ resultado desse procedimento era a cronificação.

Outro critério para internação adotado pela nova direção do hospital foi a regionalização do atendimento. Apenas o sul de Minas, as Vertentes e a Zona da Mata podiam internar seus pacientes no hospital. Tais medidas visavam a coibir o famoso "trem de doido", no qual brasileiros de várias partes do país chegavam a Barbacena pela Estação de Trem Bias Fortes (Arbex, 2013).

A partir da divisão clássica na psiquiatria entre pacientes crônicos e agudos, foi proposta a criação de um módulo experimental para casos agudos, com 120 leitos e contando com o trabalho de duas equipes multiprofissionais. Pela primeira vez, seriam anotadas em prontuários as datas de saída dos pacientes do hospital.

Posteriormente, em 1986, foram construídas cinco casas de acolhimento no interior do hospital com o objetivo de retirar dos pavilhôes pacientes crônicos com algum nível de independência, tendo em vista sua inserção no convívio social. No que concerne ao funcionamento das casas e sua relação com o hospital, temos um depoimento:

Foi uma tentativa de pegar o modelo cubano (residências intra-hospitalares). Foi no governo de Newton Cardoso que as casas foram ocupadas com pacientes de outros pavilhōes do hospital de um dia para outro, sem um trabalho para promover a desinstitucionalização, pois acreditavam que as casas seriam utilizadas para outros fins.

Eu chego ao hospital a partir de 1992 - encontro essas casas completamente indiferenciadas de pavilhão, um pavilhão com uma aparência melhorada, com uma formatação de casa. Eram casas para 24 pessoas, mas morava um pouco a mais e quando fechou o pavilhão Afonso Pena (onde é o Hospital Regional), as casas chegaram a ter 33 moradores. O pior de tudo é que a lógica hospicial permanecia. Apesar da aparência de casa, ter jardins, o modelo era hospicial: a enfermagem controlando, os médicos passando para prescrição e evolução. Não saía ninguém. 
Nessa fase eu tinha a impressão de que algo poderia ser feito a essas casas. O NESCOM [Núcleo de Educação em Saúde Coletiva] da UFMG [Universidade Federal de Minas Gerais] ficou um ano fazendo supervisão institucional, mas seu trabalho foi esvaziado e os pacientes continuaram internados. Nesse momento a direção teve uma posição avançada, mas a pressão da cidade não permitiu que ele avançasse, porque ele esperava um reconhecimento ou aprovação dos médicos psiquiatras donos de hospitais. Diferente dos outros profissionais (funcionários de folha de pagamento), o lugar do médico é na interseção do público e do privado (no privado o pagamento médico é por produtividade: AIH do leito) - tinham que manter seu "leito" (até hoje os hospitais trabalham assim). Os hospitais particulares hoje preservam isso: o leito. A direção do hospital até avançou, mas deteriorou (Profissional da enfermagem, 21 anos de trabalho no CHPB).

Esse depoimento mostra-nos que, mesmo inspirado no modelo cubano e pautado nos ideais de desospitalização, o funcionamento das residências terapêuticas, em seu cotidiano, foi absorvido pelo modus operandi do hospital psiquiátrico. Esse relato evidencia as dificuldades encontradas nos serviços de assistência ao portador de sofrimento mental de se afastar da lógica manicomial. Tais percalços, conforme veremos nos relatos posteriores, também serão encontrados nos serviços extra-hospitalares (que procuram funcionar em consonância com os princípios da Reforma Psiquiátrica Brasileira), geridos pelo município.

Atualmente Barbacena possui uma rede de assistência ao portador de sofrimento mental que conta com um CAPS 2, que funciona como porta de entrada do sistema de saúde pública, sete dias por semana, das 7 às 19 horas; um Centro de Atenção Psicossocial Álcool e Drogas (CAPS AD 3), com funcionamento de 24 horas; 28 residências terapêuticas e dois hospitais psiquiátricos particulares credenciados com o Sistema Único de Saúde (SUS). O Centro Hospitalar Psiquiátrico de Barbacena (CHPB) cede leitos para internação de portadores de quadros agudos da Macro-Região de Barbacena, que é sede de uma Gerência Regional de Saúde ${ }^{3}$.

Porém, conforme vimos no fragmento de entrevista anterior, a cidade ainda convive com uma forte cultura manicomial que se faz presente nos serviços de saúde, mesmo aqueles com apelo antimanicomial. Outro depoimento apresenta posição semelhante:

Hoje o cuidado está pior. Todos que estão lá têm qualificação, mas os cuidados se repetem da mesma forma: como se as pessoas fossem retardadas. Eles tratam o paciente como se fosse deficiente mental: falam por ele, infantilizam. A enfermagem é uma profissão muito técnica e a formação na saúde mental exige certa abstração. $\mathrm{O}$ muro não deixa a sociedade regular o profissional (Profissional da enfermagem, 21 anos de trabalho no CHPB).

3 Atualmente o Centro Hospitalar Psiquiátrico de Barbacena cede para a rede municipal de atenção à saúde mental, quatro leitos masculinos e quatro femininos, que funcionam como leito de retaguarda para o CAPS. 
Os CAPS hoje são reféns da falta de técnicos para trabalhar. Pessoas comprometidas com um novo olhar sobre a loucura. Era uma luta muito grande para não internar. $\mathrm{O} \mathrm{CHPB}$ hoje tem uma residência de psiquiatria. Olha que marca! Os preceptores são tomados pela cultura psiquiátrica da internação. Hoje, os médicos que estão nos CAPS são os residentes formados no CHPB. Como a equipe técnica tem uma formação precária, fica uma marca do hospício através da formação de residentes em psiquiatria que adotam condutas manicomiais (Profissional da psicologia, 25 anos de trabalho no CHPB).

Hoje mesmo numa reunião de equipe cogitaram a volta do eletrochoque. Um paciente delirava de forma intensa e na reunião de equipe propunham o eletrochoque. Até a lavanderia e a comida têm que ser de massa. Grandes quantidades de roupas, comida sem possibilidade de escolha. Os pacientes não conhecem laranja (só comem picado), chocolate (com embalagem). (Profissional da psicologia, 25 anos de trabalho no CHPB).

Até hoje os médicos são resistentes a assinar a alta dos pacientes. Alguns pacientes, para saírem do $\mathrm{CHPB}$ rumo às residências terapêuticas, têm que contar com a ajuda de outros médicos. Apelamos para $\mathrm{BH}$ para que a paciente de malas prontas saísse do $\mathrm{CHPB}$. Um médico chegou a "fazer a cabeça" da paciente para que não saísse do $\mathrm{CHPB}$, dizendo que ela iria passar fome, mendigar na rua. $\mathrm{O} \mathrm{CHPB}$ todo era contra também por outra razão. Eles iriam perder o emprego. Se dessem alta para todos os pacientes, haveria desemprego no hospício (Profissional da psicologia, 25 anos de trabalho no CHPB).

A lógica perversa da permanência dos restos do hospício, como um fantasma a assombrar os trabalhadores que vivem o cotidiano daquela instituição, deixa sua marca no presente. Quando vemos hoje, 33 anos após a visita de Basaglia a Barbacena, uma insistência pela volta da eletroconvulsoterapia, a resistência de médicos para assinar a alta de pacientes que poderiam morar em residências terapêuticas, a piora nos cuidados e a falta de médicos para trabalhar em serviços substitutivos, notamos, de maneira nítida, como a ausência de punição aos agentes do Estado responsáveis por aquele estado de coisas se atualiza em violência.

Violência é uma forma do passado manicomial se atualizar nos novos profissionais, como uma espécie de representação inconsciente, já que os crimes cometidos pelas gerações pregressas ficaram impunes. Nesse sentido, concordamos com a interjeição de nossa entrevistada quando menciona a formação oferecida pela residência médica em funcionamento nesse hospital: "olha que marca!"

Até início dos anos 2000 vários diretores do Centro Hospitalar Psiquiátrico de Barbacena eram médicos, proprietários de hospitais psiquiátricos na cidade ${ }^{4}$. Formou-se uma cultura entre os trabalhadores de saúde mental que visava a

\footnotetext{
4 A lei n. 8.080, de 19 de setembro de 1990, em seu artigo 26, parágrafo quarto, afirma: "Aos proprietários, administradores e dirigentes de entidades ou serviços contratados é vedado exercer cargo de chefia ou função de confiança no Sistema Único de Saúde (SUS)".
} 
acumular empregos no hospital público e no privado, adotando uma postura servil perante os proprietários de clínicas psiquiátricas. A humanização do hospital não chegou a ameaçar a indústria da loucura. Ficou restrita a uma melhora na hotelaria e nas condiçõos sanitárias do hospital. Os módulos residenciais se tornaram pequenas enfermarias, com os usuários sem nenhuma autonomia, sendo administrados pelo serviço de enfermagem da casa.

Os pacientes continuavam usando uniformes azuis e expostos a uma burocracia estatal que os transformavam em mercadorias da indústria da loucura, por intermédio de encaminhamentos à rede particular conveniada com o SUS. Esse mecanismo denominado "porta de entrada" é descrito pelos entrevistados como um plantão médico psiquiátrico de 24 horas, que contava com uma assistente social durante 8 horas por dia, de segunda à sexta-feira. Esse serviço que funcionava no Centro Hospitalar Psiquiátrico de Barbacena realizava avaliações com vistas à internação. Esse plantão se caracterizava por invariavelmente preencher o número de vagas ofertadas pelos hospitais conveniados com o SUS. Ou seja, o número de vagas disponibilizadas pelos hospitais privados determinava os encaminhamentos para internação.

Nesse contexto, temos o psiquiatra ocupando um lugar de centralidade tanto no que diz respeito ao tratamento dos pacientes quanto no que se refere à vida das pessoas envolvidas na comunidade hospitalar. Empregos em clínicas privadas, transferências de pacientes para leitos particulares, todos esses aspectos estavam sob a tutela médica. Assim, podemos fazer uma referência à Simão Bacamarte, personagem de Machado de Assis, que, ao administrar um hospital psiquiátrico, começa a influenciar, de forma decisiva, a vida da comunidade.

As pessoas querem manter o hospital psiquiátrico, têm medo de perder o emprego, de que o hospital seja municipalizado. Elas torcem para que o lugar possa ser transformado em qualquer outra coisa, mas que possam continuar no espaço. Porque a Fhemig é um bom emprego (tem creche, restaurante, igreja). Eu não aguento mais ver maus-tratos. Não são maus-tratos por maus-tratos, é o descuidar: porque em nome do cuidado você vai descuidando. Os profissionais estão muito doentes (adoecimento de profissionais que estão dentro de uma instituição total) (Profissional da enfermagem, 21 anos de trabalho no CHPB).

No que tange à psiquiatria, podemos recorrer a Pinel, que, em sua teoria, coloca o médico num lugar de centralidade na rotina hospitalar. Ao reduzir a loucura a uma enfermidade médica, Pinel deu um rosto humano a ela. Ele colocou em evidência a capacidade de julgamento das pessoas acometidas pela loucura ao afirmar que o louco não é um completo insano, pois jamais perde 
totalmente a razão. Assim, é possível identificar todo homem sensato com o alienado, identidade imprescindível para aplicação do tratamento moral. Ao reconhecer um resto de razão no alienado, o tratamento moral permite retirar o paciente do isolamento de sua cela, convidando-o a uma "convivência autêntica" (Postel \& Quetel, 1993).

Porém, o que nos interessa para discutirmos a influência do Hospital Colônia na realidade barbacenense quanto à assistência à saúde mental é o mito de Bicêtre. $\mathrm{O}$ mito da supressão das celas foi representado pelo quadro de Ch. Muller no caso dos alienados de Bicêtre. Postel e Quetel (1993) lembram que esse mito serviu para ocultar uma relação de violência que encontramos no interior da instituição psiquiátrica. Há uma nítida relação entre o mito e a organização dos asilos, no qual o poder psiquiátrico se tornará cada vez mais absoluto, pois o tratamento concebido por Pinel se baseava na persuasão pelo raciocínio. Para se obter o convencimento pelo raciocínio, o médico recorrerá à intimidação e ao fortalecimento de sua autoridade. Ou seja, para Pinel, será o médico que dará a esperança de cura ao permitir que o paciente adote seu sistema de crenças. Assim, o enfermo deve confiar absolutamente em seu médico, fazendo dele seu ideal. Porém, Postel e Quetel (1993) nos advertem da armadilha em que o médico pode ser preso ao entrar de forma arrogante num jogo de sedução narcisista.

Nesses termos, o livro reportagem de Daniela Arbex, ao apresentar alguns personagens da psiquiatria, replica, de forma acrítica, o papel central dos médicos na suposta salvação do louco. Expressões como "consertar o hospital", "mudar a ordem das coisas", seguidas de uma descrição ufanista acerca da prática médica de determinados profissionais mostra que, apesar das importantes e imprescindíveis medidas práticas de humanização do hospital psiquiátrico, a questão pineliana, presente na formação psiquiátrica, dificulta que tais profissionais prescindam de sua posição central na vida dos loucos, sob o risco de perder sua própria identidade profissional.

A declaração da profissional de enfermagem expressa de forma cabal a posição do médico como detentor do poder absoluto sobre os internos e a comunidade hospitalar.

Primeiro que pra mim a Fhemig em Barbacena não é Barbacena, é uma cidade a parte (inclusive tem uma igreja e um padre que mora lá). Tem toda a lógica de uma pequena cidade, que a gente tá tentando desmontar. Durante vários anos se tentou tirar, mas na gestão anterior. A atual voltou a fortalecer isso inclusive criando um ambulatório de saúde mental, atendendo além da contratualização do SUS, atendendo a demanda espontânea. Como se fossem independentes, uma cidade. Inclusive atendendo crianças nesse ambulatório (Profissional da enfermagem, 21 anos de trabalho no CHPB). 
Esse fragmento nos ajuda a pensar ainda a posição do médico naquilo que anteriormente denominamos de lógica do condomínio. Teríamos, assim, um espaço abrigado no qual se concentraria a fantasia de uma instituição livre das precariedades extramuros, liderada pelo psiquiatra. Estamos falando de uma fantasia narcísica que pode levar a uma servidão que acorrenta a todos numa repetição da rotina, na qual a realização da fantasia é parasitada pelo supereu (Dunker, 2011a). A substituição da função de ideal pela de um objeto encarnado cria a possibilidade para o totalitarismo e para a servidão voluntária.

O Hospital Colônia trouxe para a cidade uma cultura de segregação. Antigamente havia apenas psiquiatras e a partir deles começaram a proliferar clínicas particulares. A loucura começou a ser um bom negócio. Barbacena chegou a ter oito clínicas. De muitas delas os proprietários eram diretores do hospital colônia. Essa cultura foi criada e virou um bom negócio. A inserção dos profissionais não médicos também entrara nessa lógica. Tinham um vínculo empregatício no Estado de Minas Gerias (Hospital Colônia) e outro vínculo com as clínicas privadas. Essas pessoas não significavam uma reflexão ou um trabalho de atenção à loucura. Muitos só atualizavam prontuários, sem atender o paciente. Lembro-me de diversos pacientes do Rio de Janeiro, Conselheiro Lafaiete, gente de vários lugares que foram internados por disputa de herança. Esquecidos por seus familiares (Profissional da psicologia, 25 anos de trabalho no $\mathrm{CHPB}$ ).

Nas clínicas privadas, apesar de uma melhora nas condições sanitárias e na hotelaria, os pacientes continuavam expostos à lógica manicomial, submetidos à autoridade médica, realizando aquilo que o médico considerasse o melhor para ele.

Basaglia foi no colônia, viu os meninos de Oliveira. Declarou que aquilo era um campo de concentração. Depois foi numa clínica privada. Maquiaram o hospital, fizeram um grande lanche, mostraram uma sala de T.O., colocaram os pacientes fingindo que estavam fazendo atividades. Daí ele acabou com tudo. Disse que o que ele estava vendo era a mesma lógica manicomial (Profissional da psicologia, 25 anos de trabalho no CHPB).

\section{4. À GUISA DE CONCLUSÃO: O GOZO DA REPETIÇÃO DA POSIÇÃO PINELIANA. UM SINTOMA DA PSIQUIATRIA PÓS- HOLOCAUSTO?}

O conceito de compulsão à repetição descreve a especificidade da vivência que se dá em um campo externo à dinâmica prazer-desprazer. Por intermédio da compulsão à repetição, a vivência traumática é atualizada, com o intuito de atar psiquicamente a excitação e colocar novamente em funcionamento o princípio do prazer, bem como todas as formas de reação psíquicas ligadas a ele. O trauma 
não apenas perturba a economia libidinal como ameaça a integridade do sujeito de forma radical (Laplanche \& Pontalis, 1988).

Devido a um excesso de excitação produzido durante a situação traumática, surge uma intensa angústia. Ela se expande sobre o eu, que se vê desprotegido e desamparado. A atividade interna que se desenvolve no eu, nesse momento, repete uma reprodução abrandada da situação traumática, com o intuito de conduzir os desdobramentos da situação traumática (Freud, 1926/1996). Dessa forma, a situação de perigo externo é interiorizada e alcança um sentido para o eu.

Mas podemos falar do sintoma presente nos serviços de saúde mental de um município como se estivéssemos falando de um sujeito? Ao abordarmos o conceito de compulsão à repetição, consideramos que o sintoma social se manifesta por meio de práticas e discursos que se automatizam, independentes das estruturas de personalidade de seus agentes.

Conjecturamos que esses profissionais sofrem os efeitos das passagens inconscientes da história relegadas ao esquecimento por jogos de conveniência não explicitados quanto à demandas das minorias, cujos clamores não encontraram meios de se expressar. $\mathrm{O}$ termo Holocausto ${ }^{5}$ se refere à morte de milhares de pessoas num serviço hospitalar psiquiátrico de responsabilidade do Estado de Minas Gerais. Conforme apontamos reiteradas vezes ao longo do texto, desconhecemos qualquer tentativa, por parte do Estado, de apurar responsabilidades e buscar qualquer forma de reparação para esses atos.

Recusada as possibilidades de simbolização, o mal-estar silenciado se manifesta em atos que devem ser decifrados de maneira comparável aos sintomas dos que são escutados por um psicanalista.

Lacan (1953/1998), comentando a descoberta freudiana, a partir da posição do inconsciente, assevera que o método psicanalítico aborda o campo da realidade transindividual do sujeito. Para o autor, o inconsciente é uma parte do discurso concreto transindividual que não está à disposição do sujeito para restabelecer a continuidade do seu discurso consciente.-

Dessa forma, na perspectiva da psicanálise, podemos considerar que o sujeito não é um indivíduo na acepção da palavra. O sujeito é divido desde a sua origem, a partir de sua inserção e pertencimento a um campo simbólico, cuja sustentação é intrinsecamente coletiva.

\footnotetext{
5 Optamos por usar o termo Holocausto no título do artigo para manter o impacto da declaração fornecida por Franco Basaglia à imprensa brasileira, em 1979, na Associação Médica de Mineira, acerca do Hospital Colônia de Barbacena: "Estive hoje num campo de concentração nazista. Em lugar nenhum do mundo presenciei uma tragédia como esta”.
} 
Tais considerações nos permitem inferir que a preservação da cultura manicomial na rede de saúde mental diz respeito a um sintoma social relacionado à posição narcísica ocupada pelos psiquiatras na suposta relação terapêutica, presentes na concepção psiquiátrica pineliana. Nossos entrevistados nos mostram um movimento dos psiquiatras que vai da tentativa de humanização do atendimento manicomial a uma resistência ou recusa de assinar a alta de pacientes que seriam desinstitucionalizados. As ações em prol da humanização do hospício se encontram em consonância com uma posição de salvação dos alienados, que devem se espelhar na figura do médico como possibilidade de cura (mito de Bicêtre).

Porém, possibilitar a saída do alienado do hospício deve ser evitado. Isso representaria um golpe narcísico para o psiquiatra. Seu "condomínio" ficaria com menos habitantes, as demandas de tratamento e seu lugar de centralidade na vida dessas pessoas estariam abalados.

Esse acúmulo de experiências não incluídas nas práticas significantes, por isso mesmo excluídas do laço social, se manifesta como um pedaço excluído da cultura que encontra brecha para se manifestar.

As experiências excluídas da coletividade insistem em manifestarem-se como "cultura da segregação", "cultura da internação", "volta do eletrochoque". Até a aparente contradição entre a melhora na qualificação dos profissionais da saúde mental e a piora nos cuidados (infantilização e violência) denuncia a omissão do Estado e a recusa da sociedade em testemunhar o trauma.

A psicanálise nos ensina que o trauma é, em si, intrusivo e estranho, mas enquanto permanece estranho é sempre reavivado e irrompe em forma de repetição, sem que se possa compreendê-lo. Inferimos que as milhares de mortes ocorridas em Barbacena, fartamente noticiadas pela imprensa, foram um divisor para a chegada de uma nova geração de psiquiatras que interromperam o genocídio, mas pretendem manter o suposto alienado sob sua permanente tutela. Dessa forma, podemos afirmar que quando a sociedade não consegue elaborar os efeitos de um trauma e opta por tentar esquecer o evento traumático, esse simulacro de recalque coletivo pode produzir repetiçóes. 


\section{REFERÊNCIAS}

Arbex, D. (2013). Holocausto brasileiro - Genocídio: 60 mil mortos no maior hospício do Brasil. São Paulo: Geração editorial.

Arbex, D. (2011, 20 de novembro). Holocausto Brasileiro. 50 anos sem punição. Tribuna de Mina. Recuperado a partir de http://www.tribunademinas.com.br/ cidade/holocausto-brasileiro-50-anos-sem-punic-o-1.989343

Barbacena (2013). Prefeitura Municipal. Barbacena: PMB. Recuperado a partir de http://www.barbacena.mg.gov.br/dados.pdf

Basaglia, F. (1979) A psiquiatria alternativa: contra o pessimismo da razão, o otimismo da prática. São Paulo: Editora Brasil Debates.

Brasil. Ministério da Saúde. Secretaria de Atenção à Saúde/DAPE. (2007, Janeiro). Saúde Mental no SUS: acesso ao tratamento e mudança do modelo de atenção. Relatório de Gestão 2003-2006. Ministério da Saúde: Brasília.

Costa, J. F. (2007). História da psiquiatria no Brasil: um corte ideológico. Rio de Janeiro: Garamond.

Crise política ameaça Centro de Atenção Psicossocial (2006, Novembro). Jornal de Sábado, Barbacena.

Duarte, M. N. (1996). Ares e luzes para mentes obscuras: o Hospital Colônia de Barbacena: 1922-1946. (Dissertação de Mestrado). Universidade Federal de Minas Gerais, Programa de Pós-Graduação em Ciência Política, Faculdade de Filosofia e Ciências Humanas, Belo Horizonte, MG.

Dunker, C. I. L.(2009) A lógica do condomínio ou: O Síndico e seus descontentes. Leitura Flutuante, 1(1), 1-8.

Dunker, C. I. L. (2011a) Crítica da razão diagnóstica: mal-estar, sofrimento e sintoma na experiência psicanalítica brasileira. São Paulo: SP, Universidade de São Paulo. Mímeo.

Dunker, C. I. L. (2011b). Mal-estar, sofrimento e sintoma: releitura da diagnóstica lacaniana a partir do perspectivismo animista”. Tempo Social, 1(23), 115-136.

Firmino, H. (1982). Os porôes da loucura. Rio de Janeiro: Ed. Codecri.

Fórum Mineiro de Saúde Mental (2002). Saúde mental em Barbacena: graves retrocessos. Barbacena: [s. n.]. Mímeo. 
Foucault, M. (1991). A história da loucura na idade clássica. São Paulo: Perspectiva.

Freud, S. (1914/1996). Recordar, repetir e elaborar. In J. Salomão \& O. C. Muniz (Trads.) Obras completas (Vol. 12, pp.159-171) Rio de Janeiro: Imago. (publicado originalmente em 1914).

Freud, S. (1926/1996). Inibição, sintoma e angústia. In J. Salomão \& O. C. Muniz (Trads.) Obras completas (Vol. 20, pp.79-171) Rio de Janeiro: Imago. (publicado originalmente em 1926).

Freud, S. (1937/1996). Construções em análise. In J. Salomão \& O. C. Muniz (Trads.) Obras completas (Vol. 23, pp. 271-287) Rio de Janeiro: Imago. (Publicado originalmente em 1937).

Lacan, L. (1953/1998). Função e campo da fala e da linguagem em psicanálise. In V. Ribeiro (Trad.) . Escritos Rio de Janeiro: Jorge Zahar Editor. (Publicado originalmente em 1953).

Laplanche, J. \& Pontalis, J. (1988). Vocabulário de psicanálise. São Paulo: Martins Fontes.

Lei n. 290 (1900, 16 de agosto). Cria no Estado a Assistência de Alienados e contém outras disposições a respeito. Belo Horizonte: Coleção das leis e decretos de Minas Gerais. Recuperado a partir de http://www.almg.gov.br/consulte/legislacao/completa/ completa.html? tipo $=$ LEI $\&$ num $=290 \& \operatorname{comp}=\& a n o=1900 \& a b a=j s$ textoOriginal\#texto.

Lei n. 961 (1927, 10 de setembro). Reorganiza os serviços sanitários de Estado. Belo Horizonte: Coleção das leis e decretos de Minas Gerais. Recuperado a partir de http:/www.almg.gov.br/consulte/legislacao/completa/completa.html?tipo $=\mathrm{LEI} \&$ num $=961 \& \mathrm{comp}=\& \mathrm{ano}=1927 \& \mathrm{aba}=$ js_textoOriginal $\#$ texto.

Lei n.8.080 (1990, 19 de setembro). Dispõe sobre as condições para a promoção, proteção e recuperação da saúde, a organização e o funcionamento dos serviços correspondentes e dá outras providências. Diário Oficial da União, Brasília, DF. Recuperado a partir de http://legislacao.planalto.gov.br/legisla/legislacao. nsf/Viw_Identificacao/lei\% 208.080-1990? OpenDocument.

Lei n. 10.216 (2001, 6 de abril). Dispõe sobre a proteção e os direitos das pessoas portadoras de transtornos mentais e redireciona o modelo assistencial em saúde mental. Brasília, DF: Diário Oficial da União. 
Magro, J. B. F. (1992). A tradição da loucura: Minas Gerais: 1870/1964. Belo Horizonte: COOPMED/Editora UFMG.

Moreira, D. (1983). Psiquiatria controle e repressão social. Belo Horizonte: Vozes.

Moretzsohn, J. (1989). A história da psiquiatria mineira. Belo Horizonte: COOPMED Editora.

Nunes, S. A. (1988). Da medicina social a psicanálise. In J. Birman (Org.). Percursos na história da psicanálise (pp. 61-122). Rio de Janeiro: Editoria Taurus.

Portaria/GM n. 106 (2000, 11 de fevereiro). Institui os Serviços Residenciais Terapêuticos no âmbito do SUS. Brasília, DF: Presidência da República.

Portaria/GM n. 1.220 (2000, 7 de novembro). Criação do serviço residencial terapêutico em Saúde Mental, da atividade profissional cuidador em saúde, o grupo de procedimentos Acompanhamento de Pacientes e o subgrupo Acompanhamento de Pacientes Psiquiátricos, o procedimento Residência Terapêutica em Saúde Mental, dentre outros. Brasília, DF: Presidência da República.

Postel, J \& Quetel, C. (1993). Historia de la psiquiatria. México: Fondo de Cultura Económica, 1993.

Rodrigues, L. (1930). Instituto Raul Soares: primeira memória médico adminstrativa dos serviços de assistência a alienados. Belo Horizonte: Imprensa Official de Minas Geraes.

Russo, J. (2002). O mundo psi no Brasil. Rio de Janeiro: Jorge Zahar editores.

Silva, M. C. B. e. (2008) Repensando os porôes da loucura: um estudo sobre o Hospital Colônia de Barbacena. Belo Horizonte: Argvmentvm.

Toledo, J. (2013). Centro Hospitalar Psiquiátrico de Barbacena: 98 anos de existência. In Anais do 6 Congresso Brasileiro de História da Medicina. Barbacena: Sociedade Brasileira de História da Medicina. Recuperado a partir de http:// www.sbhm.org.br/index.asp?p=congressos_resumo\&codigo $=46$. 